\title{
Papillary Urothelial Neoplasm of Low Malignant Potential with Inverted Growth Pattern- A Case Report
}

\author{
Nanda Patil ${ }^{1}$, Shoaib Khoja ${ }^{2 *}$, Garima Agarwal ${ }^{2}$, Vaidehi Nagar ${ }^{2}$, Divya Brahmbhatt ${ }^{2}$
}

${ }^{1}$ Professor, ${ }^{2}$ Tutor, Department of Pathology, Krishna Institute of Medical Sciences; Deemed to be Univerisity, Karad, India

DOI: $10.36347 /$ sjmcr.2020.v08i04.017

| Received: 14.04.2020 | Accepted: 22.04.2020 | Published: 25.04.2020

*Corresponding author: Shoaib Khoja

Abstract

Case Report

Papillary Urothelial Neoplasm of Low Malignant Potential (PUNLMP) is a rare urothelial neoplasm seen in elderly patients. The term PUNLMP is used for noninvasive neoplasm of bladder with features of multilayering of lining epithelium and showing minimal or absent nuclear atypia. The growth pattern of these lesions is usually exophytic. We report a rare case of PUNLMP arising from bladder with inverted growth pattern in a 65 year old male patient.

Keywords: PUNLMP; Bladder; Inverted.

Copyright @ 2020: This is an open-access article distributed under the terms of the Creative Commons Attribution license which permits unrestricted use, distribution, and reproduction in any medium for non-commercial use (NonCommercial, or CC-BY-NC) provided the original author and source are credited.

\section{INTRODUCTION}

The term Papilary Urothelial Neoplasm of Low Malignant Potential (PUNLMP) has been introduced in the World Health Organization 2004 classification of tumors of the Urinary System and Male Genital Organs.

According to this classification PUNLMP is defined as a Papillary Urothelial lesion with an orderly arrangement of cells within papillae and having increased cellular proliferation exceeding the thickness of normal urothelium and having minimal to absent cytological atypia, preserved polarity of cells and rare mitosis [1]. PUNLMP with endophytic growth is a recently described term $[2,3]$.

We present a case of PUNLMP from bladder with inverted growth pattern in a 65 years old male patient.

\section{Case Report}

A 65 years male patient admitted with pain in abdomen with history of hematuria since 4 months. MRI pelvis revealed a well-defined endophytic mass arising from the posterior wall of bladder likely to represent benign polyp. Cystoscopic excision biopsy of mass was done and the specimen was sent for histolopathogical examination

Histopathological examination - Gross examination revealed a single grey white polypoidal lesion measuring $1.5 \times 0.8 \times 0.5 \mathrm{~cm}$. Cut section was grey white (fig 1, 2). Microscopy of the lesion revealed urothelial neoplasm with an endophytic growth pattern. The lesion revealed branching papillary fronds showing mutilayering of lining urothelial cells with orderly arrangement within papillae and retaining of architecture. These cells showed mildly enlarged hyperchromatic nuclei of uniform size and shape and were distributed regularly within the papillae. Mitotic figures were infrequent (fig 3,4).

Considering these features the histopathological diagnosis was given as Papillary Urothelial Neoplasm of Low Malignant Potential with inverted growth pattern.

The patient has been kept on follow up. 


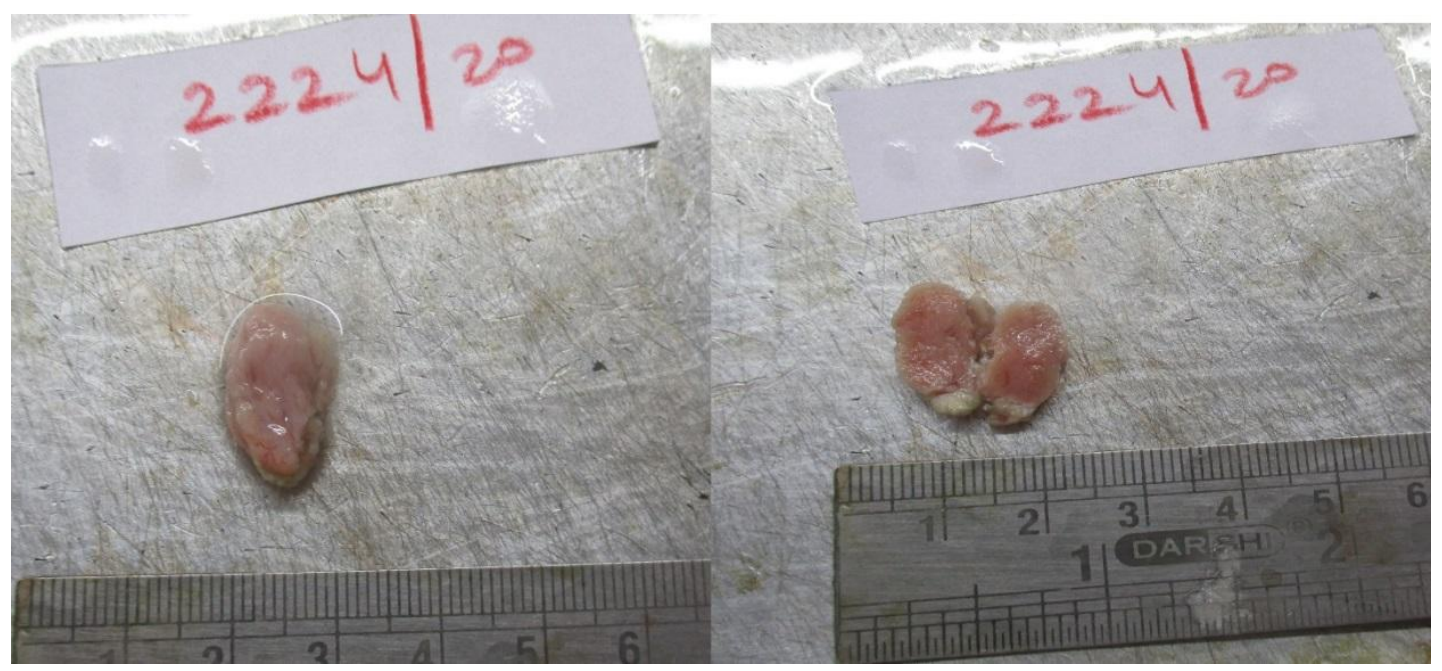

Fig-1\&2: Gross Examination reveals a single greywhite polypoidal lesion; cut section is grey white homogenous

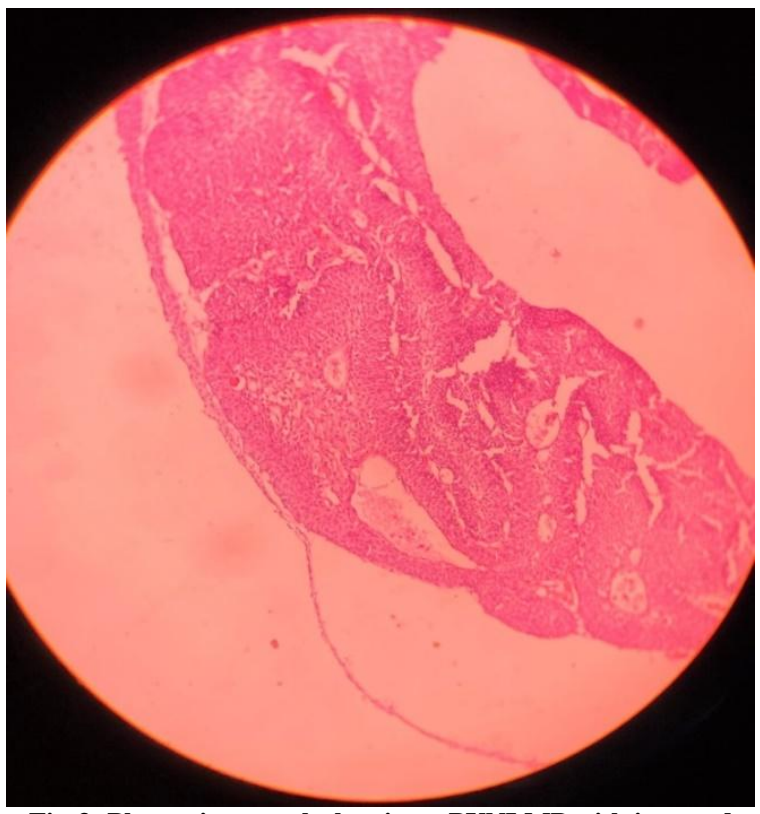

Fig-3: Photomicrograph showing a PUNLMP with inverted growth pattern (40x $\mathrm{H \& E})$

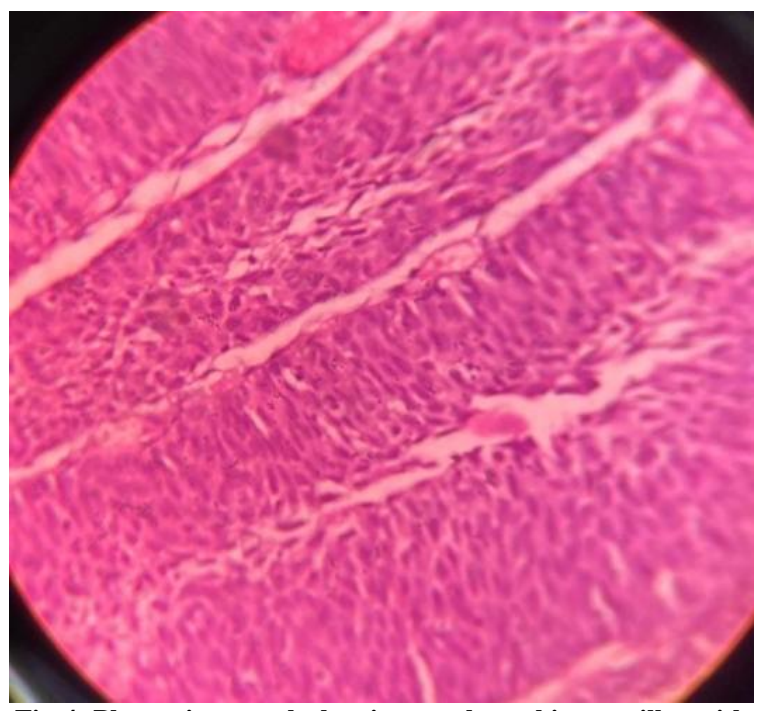

Fig-4: Photomicrograph showing non branching papillae with orderly arrangement or cells. $(400 x \mathrm{H \& E})$

\section{DISCUSSION}

PUNLMP are usually observed in male patients older than 50 years. Commonest clinical presentation of these patients is hematuria as in our case and also observed in other studies [4,5].

Most Papillary Urothelial Neoplasms present as exophytic growth in the form of finger like papillae but few show endophytic growth growth pattern. Inverted PUNLMP pattern is seen rarely [3]

Very few studies are available which describe the biological behavior of inverted PUNLMP. They have stated the uncertain clinical behavior of inverted PUNLMP [2,3].

Maxwell et al. have studied 189 PUNLMP out of which 12 revealed inverted growth pattern $(6.3 \%$ cases). The close differential diagnosis of inverted PUNLMP is Inverted Papilloma. The growth pattern of inverted PUNLMP lacks central streaming and peripheral palisading which is a characteristic feature of inverted papilloma [6].

The recurrence and progression rate of PUNLMP ranges from 3.6 to $51.9 \%[4,7,8,9]$. Out of $6.3 \%$ of inverted PUNLMP among 186 PUNLMP cases studied by Maxwell et al. all of these inverted PUNLMP revealed no recurrence of disease progression whereas overall rates of recurrence and progression to high grade carcinoma in case of PUNLMP with exophytic growth was $20.1 \%$ and $1.6 \%$ respectively with a mean follow up period of 61 months. Recurrence and progression was predominantly seen in male patients older than 50 years in their study [6]. However additional studies may be needed to verify present findings. These patients should be monitored regularly with ultrasonography for recurrence or progression. 


\section{CONCLUSION}

Papillary Urothelial Neoplasm of Low Malignant Potential with inverted growth pattern is a rare observation. These tumors have better outcome in terms of recurrence. Hence reporting of inverted pattern in PUNLMP helps in long term patient management.

\section{REFERENCES}

1. Johansson SL, Busch C. Papillary urothelial neoplasm of low malignant potential. In: Eble JN, Sauter G, Epstein JI, Sesterhenn IA, editors. Pathology \& Genetics: Tumors of the Urinary system and Male Genital Organs. Lyon, France: World Health Organization, IARC Press. 2004:115-7.

2. Epstein JI, Amin MB, Reuter VE. Urothelial neoplasms with inverted growth patterns. Biopsy Interpretation of the Bladder. Philadelphia, PA: Lippincott Williams \& Wilkins. 2010:79-93.

3. McKenney JK, Amin MB. Papillary Urothelial Neoplasm of Low Malignant Potential. Diagnostic Pathology: Genitourinary, Amirsys. 2010;9.

4. Fujii Y, Kawakami S, Koga F, Nemoto T, Kihara K. Long- term outcome of bladder papillary urothelial neoplasms of low malignant potential. BJU international. 2003 Oct;92(6):559-62.

5. Nanda Patil, Avinash Mane, Jyoti Tele, Pranita Warhate. Papillary Urothelial Neoplasm of Low Malignant Potential: A Case Report. IJSR. 20176(1):1547-48.

6. Jay P Maxwell, Cheng Wang, Nicholas Wiebe. Long-term outcome of primary Papillary Urothelial Neoplasm of Low Malignant Potential (PUNLMP) including PUNLMP with inverted growth. Diagn Pathol. 2015; 10: 3

7. Cheng L, Neumann RM, Bostwick DG. Papillary urothelial neoplasms of low malignant potential. Clinical and biologic implications. Cancer. 1999; 86:2102-8

8. Lee TK, Chaux A, Karram S, Miyamoto H, Miller JS, Fajardo DA. Papillary urothelial neoplasm of low malignant potential of the urinary bladder: clinicopathologic and outcome analysis from a single academic center. Hum Pathol. 2011;42:1799-803.

9. Montironi R, Scarpelli M, Lopez-Beltran A, Mazzucchelli R, Alberts D, Ranger-Moore J. Chromatin phenotype karyometry can predict recurrence in papillary urothelial neoplasms of low malignant potential. Cell Oncology. 2007;29:4758. 